\title{
Myocardial infarction among men below age 40
}

\author{
R. BERGSTRAND, A. VEDIN, C. WILHELMSSON, J. WALLIN, \\ H. WEDEL, AND L. WILHELMSEN
}

From the Section of Preventive Cardiology, Department of Medicine I, and Department of Roentgenology, Sahlgrenska Hospital, S-413 45 Göteborg, Sweden

SUMMARY Studies were made in Göteborg over a period of 6 years of all cases of acute myocardial infarction diagnosed among men below the age of 40. Thirty-six cases were registered and 8 of these died outside hospital. Three patients died early during the hospital stay. The remaining 25 patients were compared with a random sample from the general population in Göteborg with respect to conventional risk factors. Smoking, and high plasma cholesterol values were dominating findings among the patients, whereas there was no significant difference in blood pressure levels.

Coronary angiography was performed in 18 patients of whom 2 showed normal coronary arteries and left ventricular angiograms. These 2 patients were the only ones free from risk factors. Of the remaining 16 patients, 10 had only one vessel affected.

In Sweden, Western Europe, and the United States cardiovascular diseases dominate the mortality pattern. Ischemic heart disease alone is responsible for more deaths than any other single disease. There is a general agreement on a multifactorial aetiology of the disease. The incidence of myocardial infarction increases rapidly with age. Many authors consider that the incidence of myocardial infarction has increased during the past decades especially in younger age groups.

The purpose of the present study was to present the incidence of myocardial infarction among men who were less than 40 years of age and to characterise the patients in relation to the general population within a geographically and demographically defined area.

\section{Patients, population samples, and methods}

PATIENTS WITH MYOCARDIAL INFARCTION From 1 January 1968, all cases of acute myocardial infarction occurring in the population of Göteborg in certain age groups were registered by the Myocardial Infarction Register (Elmfeldt et al., 1975a). This register comprises 90 per cent of all surviving diagnosed cases of myocardial infarction occurring in the city. After discharge from hospital, all survivors were systematically followed up at a special Post-myocardial Infarction Clinic (Elmfeldt et al.,

Received for publication 11 March 1977 1975b). The present study comprised men aged 39 or less who suffered their infarctions between 1 January 1970 and 31 December 1975.

Non-fatal myocardial infarction was registered if 2 of the following 3 criteria were fulfilled: (1) central chest pain thought to be caused by infarction; (2) GOT and GPT rises according to a special pattern; (3) typical electrocardiographic abnormalities of recent onset (Elmfeldt et al., 1975a).

For the diagnosis acute myocardial infarction in fatal cases it had to be established that the death certificates stated this diagnosis directly or when the diagnosis on the death certificate was uncertain, that the necropsy had shown macroscopical or microscopical myocardial necrosis.

\section{POPULATION SERIES}

As the reference group for comparison with myocardial infarction patients, random samples from different age groups were selected from the total male population in Göteborg. The population samples were obtained from the municipal census list which by law must be kept up to date. The group of men between 30 and 39 years of age consisted of a random sample selected from all men in Göteborg born in 1936 to 1945 . The study was performed in 1975.

The total sample comprised 538 persons of which $366(68 \%)$ were examined. Since $34(6 \%)$ of the men were not traced, the real participation rate can be regarded as 73 per cent (366 of 504). 
INTERVIEWS, AND PHYSICAL, AND

LABORATORY INVESTIGATIONS

For all interviews, physical examinations, and laboratory investigations the same type of questionnaire, the same laboratory methods, and the same group of investigators were used for the infarction patients and for the population sample.

In order to ensure uniform collection of data, special forms were prepared. The form contained vital statistics, information of certain previous diseases, cause of death of parents, cardiovascular and respiratory symptoms, smoking habits, physical activity at work and during leisure time, for the infarction patients' situation at the onset of the disease, during the hospital stay, and at discharge.

Relative body weight was calculated by Quetletts formula

$$
\frac{\text { wt }[\mathrm{kg}]}{\mathrm{ht}[\mathrm{cm}]^{2}} \times 100
$$

(Khosla and Lowe, 1967). Obesity was defined as relative body weight over $0 \cdot 28$, corresponding to an overweight of 20 to 25 per cent (Metropolitan Life Insurance Company, 1959).

Persons who smoked at least one cigarette each day or who had stopped smoking less than 3 months before the interview were classified as smokers. Persons who had never smoked or smoked continuously for less than one month were defined as non-smokers. Other persons were regarded as exsmokers. For registration of the average tobacco consumption one cigarette was considered to be equivalent to $1 \mathrm{~g}$, one cigarillo to $2 \mathrm{~g}$, and one cigar to $5 \mathrm{~g}$. The daily tobacco consumption was divided into three groups; 1 to $14 \mathrm{~g}, 15$ to $24 \mathrm{~g}$, and $\geq 25 \mathrm{~g}$. Pipe smokers' tobacco consumption was calculated by dividing the weekly consumption in grams by 7 . In addition to the above data the type of smoking (for example cigarette smoker or pipe smoker) and inhalation habits were recorded.

Physical activity at work and during leisure time was recorded separately according to a four-step scale. At work the scale ranged from, 1: 'office work, sitting more than half the day' to 4: 'heavy work in forests, docks'; and during leisure time from 1: 'watching TV, reading' to 4: 'hard and regular physical training several times per week' (Elmfeldt et al., 1976).

Hypertension was considered to be present during the follow-up after infarction if on two consecutive outpatient visits the systolic and diastolic blood pressures were above $160 \mathrm{mmHg}$ and $95 \mathrm{mmHg}$, respectively.

Blood pressure was measured after 5 minutes' resting supine with a mercury manometer. Readings were recorded to the nearest $2 \mathrm{~mm}$. Diastolic phase $\mathrm{V}$ was used.
Cholesterol in serum was determined according to Cramér and Isaksson (1959). In the infarction patients the blood sample was taken 3 months after the acute infarction and after 12 hours' fasting. In the population series the blood sample was taken in the afternoon after 4 hours' fasting.

For registration of dyspnoea on exertion the questionnaire published by Rose and Blackburn was used (1968). All individuals who had dyspnoea when walking up a small hill or walking rapidly on level ground, or on less exertion were recorded as having dyspnoea on exertion.

Case history with respect to chest pain on exertion was also recorded according to Rose and Blackburn (1968) and angina pectoris was defined as chest pain on exertion which ceased on resting and was present more than 4 weeks before onset of acute infarction.

\section{RADIOLOGICAL INVESTIGATIONS}

Selective coronary angiography and left ventricular angiography were performed at least 3 months after infarction according to the technique described by Judkins (1968) and recorded with a $35 \mathrm{~mm}$ cine technique with a 2-plane presentation of the left ventricle. Eighteen patients were examined angiographically. The 7 remaining patients dropped out for various reasons.

TREATMENT AND FOLLOW-UP OF MYOCARDIAL INFARCTION PATIENTS

The treatment of patients after discharge from hospital was standardised and uniform rules were established by means of regular meetings with the staff attending the patients (Elmfeldt et al., 1975b). Angina pectoris and cardiac decompensation were treated according to the same principles.

All the patients were informed about the association between smoking and ischaemic heart disease and smokers were advised to stop smoking. Control examinations took place at intervals required by the clinical situation and always 3,12, 24, and 60 months after the infarction.

\section{STATISTICAL METHODS}

Patients below the age of 30 were excluded in the comparison with the population sample.

The difference of a discrete variable between the patient group and the population was analysed by a $2 \times \mathrm{n}$ contingency table. The test used was a permutation test. The statistical significances of differences between the patient group and the population of continuous variables were determined by Fisher's permutation test (Odén and Wedel, 1975). Coding of sub-results for different age groups was done by the Mantel-Haenzel procedure 
(Mantel, 1961). The $P$ values were calculated with Edgeworth's expansion of the test variables if they had the same sign (Odén and Wedel, 1975). Differences were considered statistically significant if in a 2-tailed test $2 \mathrm{P}<0.05$.

\section{Results}

Thirty-six men, all with primary infarctions, were registered by the Infarction Register during 1970 to 1975. The annual number varied between 2 and 10. Of the 36 men, 24 were between 35 and 39 years of age. The two youngest patients were 26 years of age. The annual incidence of myocardial infarction among men aged 25 to 39 years was 12 per 100000 inhabitants. Among men between 30 and 34 years of age there was a significant difference in incidence between men born in Sweden, 6 per 100000 , and immigrants born abroad, 27 per 100000 (Table 1).

Table 1 Number of men below 40 years of age who suffered myocardial infarction in Götegorg 1970-1975, and annual incidence with respect to place of birth

\begin{tabular}{|c|c|c|c|c|c|c|}
\hline Age (y) & $\begin{array}{l}\text { Place of } \\
\text { Total po } \\
\text { Abroad }\end{array}$ & $\begin{array}{l}\text { birth } \\
\text { Opulation } \\
\text { Sweden }\end{array}$ & $\begin{array}{l}\text { Patients } \\
\text { Abroad } \\
\text { Number } \\
1970- \\
1975\end{array}$ & $\begin{array}{l}\text { Annual } \\
\text { Incidence } \\
\text { per } \\
100000\end{array}$ & $\begin{array}{l}\text { Sweden } \\
\text { Number } \\
1970- \\
1975\end{array}$ & $\begin{array}{l}\text { Annual } \\
\text { incidence } \\
\text { per } \\
100000\end{array}$ \\
\hline $\begin{array}{l}25-29 \\
30-34 \\
35-39\end{array}$ & $\begin{array}{l}4200 \\
3700 \\
2500\end{array}$ & $\begin{array}{ll}17 & 100 \\
11200 \\
10 & 000\end{array}$ & $\begin{array}{l}1 \\
6 \\
7\end{array}$ & $\begin{array}{l}- \\
27 \\
46\end{array}$ & $\begin{array}{r}1 \\
4 \\
17\end{array}$ & $\begin{array}{r}- \\
28\end{array}$ \\
\hline
\end{tabular}

Eight men died outside hospital and in all cases at necropsy there was evidence of myocardial necrosis and arteriosclerotic coronary heart disease.

Twenty-eight patients reached the hospital alive. Three of these died while in hospital, all deaths occurring during the first 6 hours after admission. Twenty-five patients were discharged alive from hospital and 23 out of these men fulfilled all 3 diagnostic criteria. Two patients did not have a typical transaminase series. Because of the brief time between hospital admission and death for the 3 patients who died, diagnostic criteria could not be established in vivo and the diagnoses were based on findings at necropsy.

Height, weight, relative body weight, and obesity did not differ significantly between infarction patients and the population (Table 2). Obesity was equally common among infarction patients $(8 \%)$ and the population (9\%).

Four fathers $(16 \%)$ and one mother $(4 \%)$ of the 25 patients had died a cardiac death whereas the corresponding percentage among the population
Table 2 Weight, height, and relative weight among myocardial infarction patients and population below 40 in Göteborg

\begin{tabular}{|c|c|c|c|c|}
\hline & $\begin{array}{l}\text { Myocar } \\
\text { infarctio } \\
N=23 \\
\text { Mean }\end{array}$ & $\begin{array}{l}l \\
S D\end{array}$ & $\begin{array}{l}\text { General } \\
\text { population } \\
N=366 \\
\text { Mean }\end{array}$ & $S D$ \\
\hline $\begin{array}{l}\text { Weight (kg) } \\
\text { Height }(\mathrm{cm}) \\
\text { Relative weight } \\
(\mathbf{k g}) \times 100\end{array}$ & $\begin{array}{r}77 \cdot 0 \\
175 \cdot 2\end{array}$ & $\begin{array}{l}8.9 \\
5.0\end{array}$ & $\begin{array}{r}76 \cdot 2 \\
177 \cdot 5\end{array}$ & $\begin{array}{r}10 \cdot 0 \\
6.4\end{array}$ \\
\hline & 0.251 & 0.023 & 0.241 & 0.028 \\
\hline
\end{tabular}

was 10 per cent and 1 per cent respectively. The differences were not significant.

The percentage distribution according to smoking habits and tobacco consumption is presented in Fig. 1. Smoking was more common among infarction patients of whom only 2 were non-smokers. The tobacco consumption among smokers was higher among patients than in the population $(2 \mathrm{P}<0.01)$.

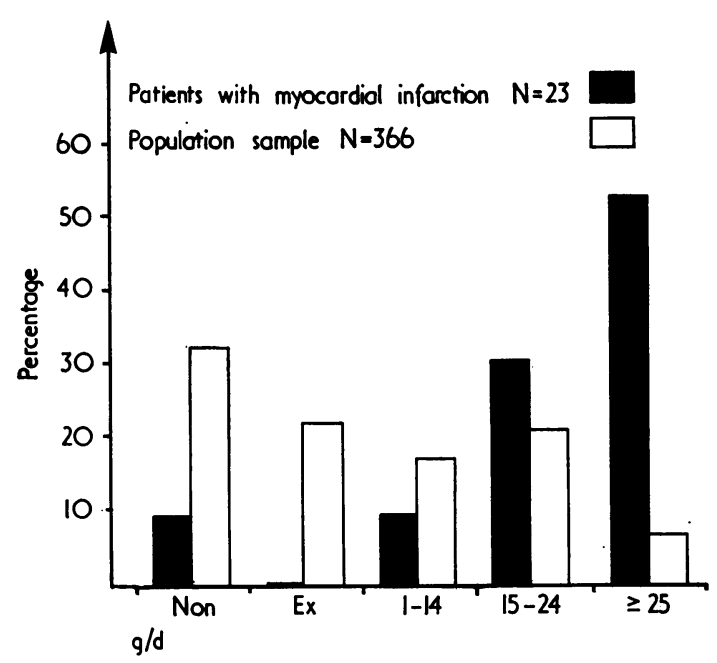

Fig. 1 Smoking habits among men with myocardial infarction less than 40 years of age in Göteborg 1970-1975 compared with the population.

The mean serum cholesterol value among patients $(7.5 \mathrm{mmol} / 1$; SD $1.1 \mathrm{mmol} / \mathrm{l})$ was higher than in the population $(6.0 \mathrm{mmol} / 1 ; S D 1.0 \mathrm{mmol} / 1$; $2 P<0.01$ ). About 60 per cent of the myocardial infarction patients had serum cholesterol values above $7.0 \mathrm{mmol} / 1$, whereas the corresponding figure for the population was 15 per cent.

The physical activity at work was higher among the myocardial infarction patients than among the 
population $(2 \mathrm{P}<0.01)$. No difference could be noted during leisure (Table 3 ).

A history of hypertension was reported by 2 patients $(9 \%)$. The prevalence of hypertension in the population was 2 per cent. Hypertension after infarction was found in 6 patients of whom 5 were 30 years of age or older. There were no differences in average blood pressure levels between the patients 3 months after their infarction and the population (Table 4).

Table 3 Physical activity among myocardial infarction patients $(N=23)$ and in general population $(N=362)$

\begin{tabular}{|c|c|c|c|c|}
\hline Grade $^{\star}$ & & 2 & 3 & 4 \\
\hline $\begin{array}{l}\text { At work } \\
\text { Myocardial infarction patients } \\
\text { Population } \\
\text { At leisure } \\
\text { Myocardial infarction patients } \\
\text { Population }\end{array}$ & $\begin{array}{l}32 \\
28\end{array}$ & $\begin{array}{l}27 \\
32 \\
36 \\
41\end{array}$ & $\begin{array}{l}41 \\
28 \\
23 \\
27\end{array}$ & $\begin{array}{r}23 \\
10 \\
9 \\
4\end{array}$ \\
\hline \multicolumn{5}{|c|}{$\begin{array}{l}\text { At work }{ }^{\star} \text { : } \\
\text { Grade } 1 \text { : office work-sitting more than half the day. } \\
\text { Grade } 2 \text { : light work but with much walking like teacher, foreman } \\
\text { etc. } \\
\text { Grade 3: most work at factories, postmen, etc. } \\
\text { Grade } 4 \text { : heavy work in forest, docks, etc. } \\
\text { At leisure: } \\
\text { Grade } 1 \text { : reading, watching TV. } \\
\text { Grade 2: walking or biking at least } 4 \text { hours per week. } \\
\text { Grade 3: gardening or regular running, swimming, football once } \\
\text { or twice a week. } \\
\text { Grade } 4: \text { hard and regular physical training several times per week. }\end{array}$} \\
\hline
\end{tabular}

Smoking habits and cholesterol levels for the patients and the population sample are presented in Fig. 2. High cholesterol levels and heavy smoking discriminate the majority of the patients. Cholesterol values were only moderately raised in the 2 nonsmoking patients.
Table 4 Blood pressures 3 months after infarction and in population

\begin{tabular}{lcllll}
\hline & Number & \multicolumn{2}{l}{$\begin{array}{l}\text { Systolic } \\
\text { (mmHg })^{\star}\end{array}$} & \multicolumn{2}{l}{$\begin{array}{l}\text { Diastolic } \\
(\mathrm{mmHg})^{\star}\end{array}$} \\
& & Mean $^{*}$ & SD & Mean $^{\text {Mean }}$ & SD \\
\hline Patients & 23 & 137 & 22 & 89 & 13 \\
Population & 366 & 133 & 14 & 84 & 10
\end{tabular}

A history of chest pain suggesting angina pectoris present more than one month before infarction among the patients $(22 \%)$ was more common than chest pain in the population $(4 \%)$. The prevalence of other symptoms such as breathlessness on exertion and other diseases such as diabetes, gall stones, or kidney stones was low, both among patients and the population.

Among the patients angiographically examined 10 had 1-vessel disease, 2 had 2-vessel disease, and 2 had 3-vessel disease. Normal coronary vessels could be seen in 3 patients of whom 2 also had normal left ventricular angiograms. In 1 patient the right coronary artery could not be visualised. There was no association between angiographic findings and risk factors. The details of the radiographic study will be described further in a forthcoming study (J. Wallin et al., unpublished observations).

\section{Discussion}

Great efforts have been spent to define risk factors for myocardial infarction. Many factors are intercorrelated and some are age- and sex-dependent. In the present study we, therefore, chose to analyse a limited age group of men. The patients studied can be regarded as representative for acute myocardial infarction in patients below 40 years of age (Elmfeldt et al., 1975a, b). Among men below 65 the incidence of myocardial infarction was low, about

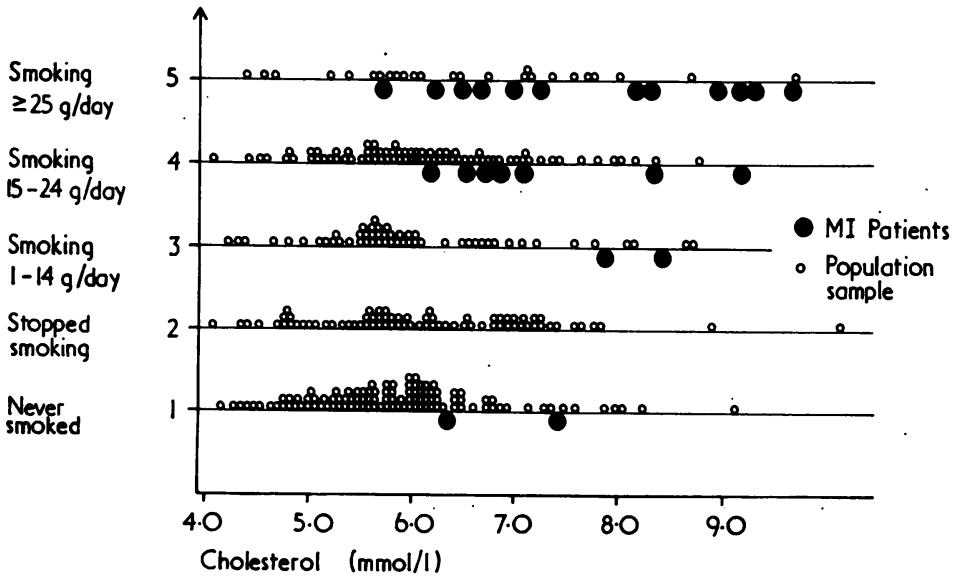

Fig. 2 Combination of the risk factors smoking and cholesterolaemia in the patients (O) and in the population sample (O). 
250/100 000, in Göteborg compared with other WHO centres (World Health Organization, 1976). Between 2 and 3 per cent of all cases were below 40 (Elmfeldt et al., 1975a).

It is known that the non-participants differ from participants in population studies (Wilhelmsen et al., 1976). Certain differences in the risk factor profile between non-fatal and fatal myocardial infarction have been suggested (Romo, 1972; Tibblin et al., 1975). The fatal cases might have been more heavily burdened by risk factors than non-fatal cases. This problem has been discussed in a previous paper (Elmfeldt et al., 1976). Similarily smoking may be more prevalent among the non-participants in the population sample whereas high cholesterol values and hypertension were probably not more common among them. A check of hospital records for the non-participants of the present population sample has described a higher number of men than expected with alcoholic problems, but no excess of somatic diseases.

The present study supports previous investigations that obesity is not a major risk factor for acute myocardial infarction (Truett et al., 1967; Blacket et al., 1973; Tibblin et al., 1975). The difference between serum cholesterol values in the patients and the population was greater in this study than for older age groups previously presented by Elmfeldt et al. (1976). It seems as though a high cholesterol value is a stronger risk factor among younger subjects. Heavy tobacco smoking is also a stronger risk factor (Elmfeldt et al., 1976). These observations are supported by findings from other studies (Gertler et al., 1950; Walker and Gregoratos, 1967).

With respect to smoking and high serum cholesterol values our results could not be seriously distorted by the non-participants of the population sample. If all non-participants were smokers there would still be a significant difference between the infarction patients and the general population. It is unlikely that the cholesterol levels would differ between the participants and non-participants.

It seems as though hypertension is not an important risk factor below the age of 40 . It is probable that not only the pressure levels but also the duration of the hypertensive disease are of importance in increasing the risk for acute myocardial infarction. Thus, the same risk factors, with some uncertainty for hypertension, operate among men 39 years of age and younger. These findings are supported by other studies (Blacket et al., 1973; Dolder and Oliver, 1975).

The higher prevalence of previous angina pectoris in infarction patients indicates that many patients have had long-standing ischaemic heart disease.
The high incidence of myocardial infarction among men born abroad is not explained by an overrepresentation of subgroups of immigrants from countries where the incidence of ischaemic heart disease is higher than in Sweden, for instance Finland (World Health Organization, 1976).

Physical inactivity at work is usually considered to be a risk factor for myocardial infarction. The present study showed an inverse and unexpected relation. A more detailed interpretation of this finding awaits corroboration.

Despite a different study design the findings of the present study agree with those of Dolder and Oliver (1975) regarding smoking, high serum cholesterol values, and hypertension. Relative body weight and obesity are comparable with the findings in Los Angeles/Atlanta, Auckland, and Edinburgh. Physical activity was, however, not examined in that study.

As early as 1939 the possibility of myocardial infarction without coronary artery occlusion was mentioned (Friedberg and Horn, 1939). Some authors have earlier shown that about 10 per cent of patients who have fulfilled the conventional criteria for myocardial infarction have angiographically normal coronary arteries (Khan and Haywood, 1974; Savran et al., 1976). As long as the clinical diagnosis is based on indirect criteria there is a possibility of false positive cases. Moreover, there are several conditions other than atherosclerosis that can result in clinical acute myocardial infarction (Cheitlin et al., 1975). The relation between the frequency of findings in the different coronary arteries is supported by other investigations (Möttönen, 1970; Valentine et al., 1973; Savran et al., 1976; L. Wilhelmsen et al., unpublished observations). Several patients had the involvement restricted to one or two vessels only.

Two of the patients showed normal coronary arteries as well as a normal left ventricular angiogram and were the only ones who were free from smoking, hypertension, and high plasma cholesterol values.

In conclusion, the patients were heavy smokers and had high serum cholesterol values. However, the angiographic examinations indicated that the changes in the coronary arteries tended to be localised to one vessel only. Thus, a myocardial infarction may not constitute an end stage of advanced coronary artery disease.

\section{References}

Blacket, R. B., Leelarthaepin, B., Palmer, A. J., and Woodhill, J. M. (1973). Coronary heart disease in young men: a study of seventy patients with a critical review of etiological 
factors. Australian and New Zealand fournal of Medicine, 3, 39-62.

Cheitlin, M. D., McAllister, H. A., and de Castro, C. M. (1975). Myocardial infarction without atherosclerosis. Fournal of the American Medical Association, 231, 951-959. Cramér, K., and Isaksson, B. (1959). An evaluation of the Theorell method for the determination of total serum cholesterol. Scandinavian fournal of Clinical and Laboratory Investigation, 11, 213-216.

Dolder, M. A., and Oliver, M. F. (1975). Myocardial infarction in young men. Study of risk factors in nine countries. British Heart fournal, 37, 493-503.

Elmfeldt, D., Wilhelmsen, L., Tibblin, G., Vedin, A. J., Wilhelmsson, C-E., and Bengtsson, C. (1975a). Registration of myocardial infarction in the city of Göteborg, Sweden. A community study. Fournal of Chronic Diseases, 28, 173-186.

Elmfeldt, D., Wilhelmsen, L., Tibblin, G., Vedin, A. J., Wilhelmsson, C-E., and Bengtsson, C. (1975b). A Postmyocardial Infarction Clinic in Göteborg, Sweden. A follow-up of MI patients in a specialized outpatient clinic. Acta Medica Scandinavica, 197, 497-502.

Elmfeldt, D., Wilhelmsson, C., Vedin, A., Tibblin, G., and Wilhelmsen, L. (1976). Characteristics of representative male survivors of myocardial infarction compared with representative population samples. Acta Medica Scandinavica, 199, 387-398.

Friedberg, C. K., and Horn, H. (1939). Acute myocardial infarction not due to coronary artery occlusion. fournal of the American Medical Association, 112, 1675-1679.

Gertler, M. M., Garn, S. M., and White, P. D. (1950). Diet, serum cholesterol and coronary artery disease. Circulation, 2, 696-704.

Judkins, M. P. (1968). Percutaneous transfemoral selective coronary arteriography. Radiologic Clinics of North America, 6, 467-492.

Khan, A. H., and Haywood, L. J. (1974). Myocardial infarction in nine patients with radiologically patent coronary arteries. New England fournal of Medicine, 291, 427-431.

Khosla, T., and Lowe, C. R. (1967). Indices of obesity derived from body weight and height. British fournal of Preventive and Social Medicine, 21, 122-128.

Mantel, N. (1961). Chi-square tests with one degree of freedom. Extensions of the Mantel-Haenszel procedure. Fournal of American Statistical Association, 58, 690-700.
Metropolitan Life Insurance Company (1959). Rise in mortality last year. Statistical Bulletin, Metropolitan Life Insurance Company, 40, 1-32.

Möttönen, M. (1970). Myocardial infarction and coronary atherosclerosis among and comparison between urban and rural population in Finland. Beiträge zur Pathologie, $142,64-70$.

Odén, A., and Wedel, H. (1975). Arguments for Fisher's permutation test. Annals of Statistics, 3, 518-520.

Romo, M. (1972). Factors related to sudden death in acute ischemic heart disease. A community study in Helsinki. Acta Medica Scandinavica, Suppl. 547.

Rose, G. A., and Blackburn, H. (1968). Cardiovascular Survey Methods. Monograph series no. 56, W.H.O., Geneva.

Savran, S. V., Bryson, A. L., Welch, T. G., Zaret, B. L., McGowan, R. L., and Flamm, M. D., Jr. (1976). Clinical correlates of coronary cineangiography in young males with myocardial infarction. American Heart fournal, 91, 551-555.

Tibblin, G., Wilhelmsen, L., and Werkö, L. (1975). Risk factors for myocardial infarction and death due to ischemic heart disease and other causes. American fournal of Cardio$\log y, 35,514-522$.

Truett, J., Cornfield, J., and Kannel, W. (1967). A multivariate analysis of the risk of coronary heart disease in Framingham. Fournal of Chronic Disease, 20, 511-524.

Valentine, P. A., Hare, W. S. C., and Sloman, J. G. (1973). Angiographic findings in young patients with cardiac infarction and their relation to risk factors. Singapore Medical fournal, 14, 341-343.

Walker, W. J., and Gregoratos, G. (1967). Myocardial infarction in young men. American fournal of Cardiology, 19, 339-343.

Wilhelmsen, L., Ljungberg, S., Wedel, H., and Werkö, L. (1976). A comparison between participants and nonparticipants in a primary preventive trial. Fournal of Chronic Diseases, 29, 331-339.

World Health Organization, Regional Office for Europe (1976). Myocardial Infarction Community Registers. Public Health in Europe 5, 59, Copenhagen.

Requests for reprints to Dr Robert Bergstrand, Department of Medicine I, Sahlgrenska Hospital, S-413 45 Göteborg, Sweden. 